\title{
Acute effects of inspiratory pressure support during exercise in patients with COPD
}

\author{
A. van 't Hul*,\#, R. Gosselink", P. Hollander,+, P. Postmus ${ }^{\S}$, G. Kwakkel*,\#
}

Acute effects of inspiratory pressure support during exercise in patients with COPD. A. van 't Hul, R. Gosselink, P. Hollander, P. Postmus, G. Kwakkel. (C) ERS Journals Ltd 2004.

ABSTRACT: The aim of the present study was to evaluate the acute effects of inspiratory pressure support (IPS) of $5 \mathrm{cmH}_{2} \mathrm{O}$ (IPS5) and $10 \mathrm{cmH}_{2} \mathrm{O}$ (IPS10) on exercise endurance.

Forty-five patients with COPD (mean forced expiratory volume in one second $\left(F E V_{1}\right)=39 \pm 14 \%$ pred $)$ performed three constant-load endurance tests on a cycle ergometer at 75\% of maximal workload. One test was without IPS, one test with IPS5, and one with IPS10. No statistically significant difference was found in exercise endurance between tests without IPS and IPS5 (4.2 \pm 2.6 versus $4.4 \pm 2.9 \mathrm{~min})$.

In contrast, IPS10 resulted in a statistically significant increase in endurance compared with exercise without IPS (6.3 \pm 6.7 versus $4.2 \pm 2.6 \mathrm{~min})$, as well as compared with exercise with IPS5 $(6.3 \pm 6.7$ versus $4.4 \pm 2.9 \mathrm{~min})$. A wide scatter in individual responses to IPS was found, ranging from a deterioration of $1.6 \mathrm{~min}(-36 \%)$ to an improvement of $16.3 \mathrm{~min}(+445 \%)$. In only 15 patients, the increase in endurance exceeded the upper limit of the $95 \%$ confidence interval. Stepwise multiple regression analysis showed that maximal inspiratory pressure was the most important determinant of the increase in exercise endurance due to the application of IPS10.

It was concluded that in contrast to inspiratory pressure support of $5 \mathrm{cmH}_{2} \mathrm{O}$, the application of inspiratory pressure support of $10 \mathrm{cmH}_{2} \mathrm{O}$ during exercise resulted in a statistically significant improvement in exercise endurance in patients with COPD compared with exercise without inspiratory pressure support. However, on an individual basis, large differences in responses were found. Inspiratory muscle weakness was revealed as a determinant of improvement in exercise endurance due to the application of inspiratory pressure support of $10 \mathrm{cmH}_{2} \mathrm{O}$, explaining only $24 \%$ of the variance in outcome.

Eur Respir J 2004; 23: 34-40.
*Dept of Physiotherapy, ${ }^{\S}$ Dept of Pulmonology, VU University Medical Centre, and ${ }^{+}$Faculty of Human Movement Sciences, and ${ }^{*}$ Institute for Fundamental and Clinical Human Movement Science, "Vrije Universiteit", Amsterdam, The Netherlands. "Respiratory Rehabilitation and Respiratory Division, University Hospitals, Katholieke Universiteit, Leuven, Belgium.

Correspondence: A. van 't Hul

Dept of Physiotherapy

VU University Medical Centre

P.O. Box 7057

1007 MB Amsterdam

The Netherlands

Fax: 31204440469

E-mail: aj.vthul@vumc.nl

Keywords: Assisted ventilation

chronic obstructive pulmonary disease exercise

pulmonary rehabilitation

Received: February 142003

Accepted after revision: July 192003

This study was supported by a grant from the Dutch Asthma Foundation (grant 3.2.99.28).
Pulmonary rehabilitation programmes result in significant improvements in exercise capacity and quality of life in patients with chronic obstructive pulmonary disease (COPD) [1]. Exercise training has been elicited as the cornerstone component of such programmes [2]. Several interventions may be applied during exercise to improve training tolerance in patients with COPD, such as noninvasive ventilatory support (NIVS) [3]. A recent systematic review on the acute effects of NIVS in patients with COPD revealed statistically significant summary effect sizes for the outcome measures, exertional dyspnoea and exercise endurance, in favour of NIVS [4]. In all studies conducted on the acute effects of NIVS during exercise, to date, the effects of NIVS were compared with a "sham" type of NIVS in the form of continuous positive airway pressure (CPAP) of $1 \mathrm{cmH}_{2} \mathrm{O}$ (CPAP1). However, it could be argued that the use of CPAP1 as a sham type of NIVS, requiring a breathing circuit (tubing and valve system of the ventilator), may result in an additional breathing resistance and subsequently become a deterrent to exercise performance. If so, this would lead to an overestimation of the effect of NIVS on exercise performance. To the best of the authors' knowledge, there are no studies available regarding the minimal intensity of NIVS required to compensate for the added breathing resistance resulting from the breathing circuit during exercise. However, it is suggested from studies in patients weaning from mechanical ventilation that $5 \mathrm{cmH}_{2} \mathrm{O}$ is an inspiratory assist intensity required to overcome the additional work of breathing resulting from the ventilator plus tubing [5]. On this basis it was hypothesised that inspiratory pressure support (IPS) of $5 \mathrm{cmH}_{2} \mathrm{O}$ (IPS5) during exercise would have no effect on exercise endurance.

Regardless of the positive direct effects of NIVS on the group level, large differences were found in exercise responses between individual COPD patients. For instance in a study by KEILTY et al. [6], improvements in walking distance as a result of the application of NIVS ranged 5-216\%. For the purpose of implementation of NIVS in clinical practice, such as in exercise training during rehabilitation, it would be helpful if patient characteristics were recognised on the basis of which improvements in exercise endurance due to NIVS could be predicted. Since unloading the inspiratory muscles is found to be an important mechanism of the direct improvements in exertional dyspnoea and exercise endurance [7, 8], it may be hypothesised that inspiratory muscle performance, such as maximal inspiratory pressure $(P I, \max )$, is an important determinant.

The aim of the present study was to evaluate the direct effects of NIVS on exercise endurance during exercise, in the 
form of IPS of 5 and $10 \mathrm{cmH}_{2} \mathrm{O}$ (IPS10), by comparison with a test without NIVS in patients with COPD. In addition, determinants of the relative improvement in exercise endurance due to the application of NIVS during exercise were investigated.

\section{Methods}

\section{Study population}

Patients with COPD, according to the criteria set by the Global Initiative for Obstructive Lung Disease scientific committee [9], referred for pulmonary rehabilitation were asked to participate in the present study. Patients had to meet the following inclusion criteria: 1) forced expiratory volume in one second (FEV1) $\leqslant 70 \%$ predicted; 2 ) the presence of a breathing reserve of $<30 \%$ of maximal voluntary ventilation (defined as $37.5 \times \mathrm{FEV} 1$ ) at peak exercise; 3 ) age between 40-75 yrs; 4) absence of other pathological conditions that could contribute to exercise limitation; and 5) informed consent was given. The Ethical Committee of the VU Medical Centre, Amsterdam, approved the study.

\section{Measurements}

Spirometry, plethysmography and single-breath diffusing capacity were performed according to the European Respiratory Society (ERS) recommendations [10]. The method of BLACK and HYATT [11] was used for the measurements of $P \mathrm{I}$,max and maximal expiratory pressure $(P \mathrm{E}, \max )$. Inspiratory muscle endurance $(P \mathrm{I}$,end) was assessed by a 2 -min maximal incremental inspiratory threshold-loading test [12]. Outcome on this test was related to reference values obtained in the authors' own laboratory [13].

A symptom-limited incremental cycle exercise test was conducted according to the ERS recommendations [14]. The test was performed on a calibrated, electrically braked cycle ergometer (WLP 904; Lode, Groningen, The Netherlands) at a pedalling rate of 60 revolutions $\cdot \mathrm{min}^{-1}$. During testing, work rate was increased by $10 \%$ of the estimated maximal workload until exhaustion. Maximal heart rate was determined using the RR interval from a three-lead electrocardiogram (HP78351A; Hewlett Packard, Andover, MA, USA). Peak minute ventilation $\left(V^{\prime}\right.$ E,peak; $\mathrm{L} \cdot \mathrm{min}^{-1}$ at body temperature and ambient pressure, and saturated with water vapour) and peak oxygen uptake $\left(V^{\prime} \mathrm{O}_{2}\right.$, peak; $\mathrm{mL} \cdot \mathrm{min}^{-1}$, standard temperature pressure dry) were measured with a breath-by-breath automated exercise metabolic system (Vmax229; Sensormedics, Yorba Linda, CA, USA). Thirty minutes before the start of each test, the airflow sensor was calibrated with a 3 -L syringe and gas analysers were calibrated against known gases. Arterial blood samples were drawn from an indwelling catheter in the radial artery at rest and at maximal exercise. Maximal work rate $\left(\mathrm{W}\right.$, max) and $V^{\prime} \mathrm{O}_{2}$,peak were related to the reference values of JONES and co-workers $[15,16]$. $V^{\prime}$ E,peak was related to the predicted maximal voluntary ventilation [17]. After the test, patients were asked to state their main reason for stopping exercise, i.e. intolerable exertional dyspnoea, leg fatigue or a combination of these.

Symptom-limited exercise endurance was determined with a constant-load exercise test on a cycle ergometer at $75 \%$ of the previously determined $\mathrm{W}$,max. The same cycle ergometer was used in the maximal exercise test. Patients were instructed to exercise for as long as possible. They were told to stop the exercise only when dyspnoea became intolerable and/or the required pedalling rate $\left(60\right.$ revolutions $\left.\cdot \mathrm{min}^{-1}\right)$ could not be kept up due to leg fatigue. During the test, encouragements were given every $2 \mathrm{~min}$. If exercise endurance exceeded $20 \mathrm{~min}$, the observer terminated the test. The test started when patients felt comfortable, and heart rate and oxygen saturation levels were at individual resting values. Before the tests, other forms of general exercise (testing) were avoided, and each test was preceded by a rest period of $\geqslant 15 \mathrm{~min}$. Ventilatory and metabolic responses were measured using the same metabolic cart as in the incremental exercise test. Data were averaged over 20 -s time intervals. Ventilatory variables included the measurement of inspiratory capacity (IC) at rest and at 2-min intervals during the test without IPS. To perform the IC manoeuvre, patients were instructed to inhale fairly quickly to total lung capacity after the end of a normal breath. The manoeuvre ended with a normal, unforced expiration [18]. In the tests with IPS, the metabolic cart was connected to the expiratory port of the ventilator and used in the mixing chamber mode. Patients were requested not to eat or drink tea or coffee $2 \mathrm{~h}$ before each visit. The outcome of a constant-load cycle test has been shown to be highly reproducible in patients with COPD [19].

Chronic exertional dyspnoea was scored using the Medical Research Council (MRC) dyspnoea scale. The MRC dyspnoea scale allows classification of perceived breathlessness into five grades [20]. Health status was assessed by means of the St George's Respiratory Questionnaire (SGRQ). The SGRQ is a self-report questionnaire and scores health status in three components: symptoms (dyspnoea, wheezing, coughing), activity (the severity to which activities of daily living are impaired by dyspnoea) and impacts (the influence of respiratory symptoms on social participation) [21].

\section{Study design}

Measurements took place during three visits. On the first visit, patients performed pulmonary function tests and a symptom-limited incremental exercise test. On the second visit, 1-2 weeks later, an endurance test was performed without IPS, and patients were familiarised with exercising with IPS because it was anticipated that exercise performance on IPS was susceptible to learning effects. On the third visit, two endurance tests were performed with IPS5 and IPS10, in a random order.

\section{Noninvasive ventilatory support}

NIVS was provided as IPS set at 5 and $10 \mathrm{cmH}_{2} \mathrm{O}$ (Raphael; Hamilton AG, Thäzüns, Switzerland). The flow trigger was set at $3 \mathrm{~L} \cdot \mathrm{min}^{-1}$, i.e. the lowest possible value, and the inspiratory oxygen fraction at $21 \%$. This ventilator has a capacity to support $V^{\prime} \mathrm{E}$ up to $50 \mathrm{~L} \cdot \mathrm{min}^{-1}$ with a response time of $145 \mathrm{~ms}$ and a maximal inspiratory flow rate of $180 \mathrm{~L} \cdot \mathrm{min}^{-1}$. Patients were attached to the ventilator via corrugated tubing and mouthpiece, and a noseclip was applied. The dead space of the mouthpiece was $<15 \mathrm{~mL}$. It is the authors' experience that a mouthpiece is the most practical interface for the application of NIVS during exercise, because it produces less leakage of air compared with face masks and is better tolerated by patients. Ventilator inspiratory and expiratory breathing circuits were separated, which prevents the possibility of rebreathing.

\section{Statistical analysis}

Results are expressed as mean $\pm \mathrm{SD}$. Differences in exercise endurance and physiological responses between the three constant-load tests were examined with a one-way analysis of variance. Post hoc analyses were performed with appropriate Bonferroni correction for multiple comparisons. Pearsons' 
correlation coefficients were calculated between the improvement in endurance with IPS10 and age, body length, body weight, pulmonary function and respiratory muscle performance indices, and physiological responses at peak exercise during the symptom-limited incremental and constant-load exercise test. Subsequently, a stepwise multiple regression analysis was performed to determine factors independently contributing to the improvement in exercise endurance due to the application of IPS10. Based on the literature, variables considered for use in the analysis were maximal respiratory pressures, inspiratory muscle endurance, end-exercise $V^{\prime} \mathrm{E}_{2}$ during the constant-load test without IPS, arterial carbon dioxide tension $\left(\mathrm{Pa}, \mathrm{CO}_{2}\right)$ at rest and $\mathrm{Pa}, \mathrm{CO}_{2}$ at peak exercise during the symptom-limited incremental exercise test [7, 8]. To prevent exclusion of important independent variables as a result of lack of power (type-II or $1-\beta$ error), all variables from the univariate regression analysis with a $p$-value of $<0.20$ were entered in the prediction model. For all tests, a two-sided significance level of 0.05 was used.

\section{Results}

\section{Patient characteristics}

Table 1 illustrates the main characteristics of subjects included in the present study. Forty-five patients participated in the study with a mean age of $67 \pm 7$ yrs and a mean FEV1 of $1.06 \pm 0.40 \mathrm{~L}(39 \pm 14 \%$ pred).

Table 2 shows the results of the symptom-limited incremental exercise tests. Exercise capacity was markedly reduced in the patients. On average, the breathing reserve at maximal exercise was only $6 \pm 17 \%$. Blood gases at rest and during exercise could be obtained in 33 patients. All but three patients had an increase in $P \mathrm{a}, \mathrm{CO}_{2}$ at maximal exercise compared with the resting value.

\section{Chronic exertional dyspnoea and health status}

All participating patients had significant chronic exertional dyspnoea. Twenty-four patients had an MRC score of 3 ("I

Table 1. - Characteristics of the 45 subjects

\begin{tabular}{|c|c|c|}
\hline & Values & $\%$ pred \\
\hline Age yrs & $67 \pm 7$ & \\
\hline $\mathrm{F} / \mathrm{M}$ & $12 / 33$ & \\
\hline Height m & $1.71 \pm 0.08$ & \\
\hline Weight kg & $69 \pm 11$ & \\
\hline $\mathrm{BMI} \mathrm{kg} \cdot \mathrm{m}^{-2}$ & $23.5 \pm 3.5$ & \\
\hline \multicolumn{3}{|l|}{ Pulmonary function } \\
\hline FEV1 L & $1.06 \pm 0.39$ & $39 \pm 13$ \\
\hline FVC L & $2.95 \pm 0.81$ & $82 \pm 19$ \\
\hline FEV1/FVC & $0.35 \pm 0.11$ & $46 \pm 15$ \\
\hline RV L & $4.19 \pm 1.16$ & $180 \pm 55$ \\
\hline FRC L & $5.29 \pm 1.20$ & $161 \pm 36$ \\
\hline TLC L & $7.46 \pm 1.42$ & $120 \pm 20$ \\
\hline$D \mathrm{~L}, \mathrm{CO} \mathrm{mmol} \cdot \mathrm{kPa}^{-1} \cdot \mathrm{min}^{-1}$ & $3.81 \pm 1.34$ & $45 \pm 17$ \\
\hline$P \mathrm{I}, \max \mathrm{cmH}_{2} \mathrm{O}$ & $62 \pm 17$ & $64 \pm 19$ \\
\hline$P$ E, $\max \mathrm{cmH}_{2} \mathrm{O}$ & $107 \pm 33$ & $60 \pm 17$ \\
\hline$P$ I,end $\mathrm{cmH}_{2} \mathrm{O}$ & $31 \pm 13$ & $44 \pm 18$ \\
\hline \multicolumn{3}{|c|}{$\begin{array}{l}\text { Data are presented as mean } \pm 1 \text { SD unless otherwise stated. } \% \text { pred: } \\
\% \text { predicted; F: female; M: male; BMI: body mass index; FEV1: forced } \\
\text { expiratory volume in one second; FVC: forced vital capacity; RV: } \\
\text { residual volume; FRC: functional residual capacity; TLC: total lung } \\
\text { capacity; } D \mathrm{~L}, \mathrm{CO} \text { : transfer factor for carbon monoxide; } P \mathrm{I}, \mathrm{max} \text { : maximal } \\
\text { inspiratory pressure; PE,max: maximal expiratory pressure; PI,end: } \\
\text { inspiratory muscle endurance. }\end{array}$} \\
\hline
\end{tabular}

Table 2. - Incremental exercise test in the 45 subjects

\begin{tabular}{lc}
\hline & Value \\
\hline $\mathrm{W}$, max W & $62 \pm 25$ \\
$\%$ pred & $45 \pm 18$ \\
$V^{\prime} \mathrm{O}_{2}$, peak $\mathrm{L} \cdot \mathrm{min}^{-1}$ & $1.00 \pm 0.33$ \\
$\%$ pred & $54 \pm 18$ \\
$V^{\prime} \mathrm{E}$, peak & $39.0 \pm 18$ \\
$\% \mathrm{MVV}$ & $94 \pm 16$ \\
$\mathrm{Heart}$ rate beats $\cdot \mathrm{min}^{-1}$ & $121 \pm 17$ \\
$\%$ pred & $79 \pm 12$ \\
$\mathrm{Blood}$ gases & \\
$P \mathrm{a}, \mathrm{O}_{2} \mathrm{kPa}$ & $10.3 \pm 1.5$ \\
$\mathrm{Rest}$ & $8.2 \pm 1.4$ \\
Peak exercise & \\
$P \mathrm{a}, \mathrm{CO}$ kPa & $5.1 \pm 0.6$ \\
$\mathrm{Rest}$ & $5.8 \pm 0.7$ \\
Peak exercise & \\
$\mathrm{Sa}, \mathrm{O}_{2} \%$ & $95 \pm 3$ \\
$\mathrm{Rest}$ & $89 \pm 4$ \\
Peak exercise & \\
\hline
\end{tabular}

Data are presented as mean \pm 1 SD unless otherwise stated. W,max: maximal workload; $V^{\prime} \mathrm{O}_{2}$,peak: peak pulmonary oxygen uptake; $V^{\prime}$ E,peak: peak minute ventilation; $P \mathrm{a}, \mathrm{O}_{2}$ : arterial oxygen tension; $\mathrm{Pa}, \mathrm{CO}_{2}$ : arterial carbon dioxide tension; $\mathrm{Sa}, \mathrm{O}_{2}$ : arterial oxyhaemoglobin saturation.

walk slower than people of the same age on the level because of breathlessness or have to stop for breath when walking at my own pace on the level"). Twenty-one patients had a score of 4 ("I stop for breath after walking 100 yards or after a few minutes on the level"). Also health status, measured by the SGRQ was markedly impaired (table 3).

\section{Effects of inspiratory pressure support on exercise endurance}

Results of the constant-load exercise tests are presented in table 4. Seven of the 45 patients expressed their discomfort about the wearing of a noseclip and/or dryness of the throat during exercise with IPS. However, all patients were able to complete the protocol. No statistically significant difference was found in exercise endurance between exercise with IPS5 and a test without IPS $(4.4 \pm 2.9$ versus $4.2 \pm 2.6 \mathrm{~min}, \mathrm{p}=0.70)$. However, the application of IPS10 during exercise resulted in a statistically significant increase in exercise endurance compared with IPS5 (6.3 \pm 6.7 versus $4.4 \pm 2.9 \mathrm{~min}, \mathrm{p}<0.01)$, as well as compared with exercise without IPS $(6.3 \pm 6.7$ versus $4.3 \pm 2.6 \mathrm{~min}, \mathrm{p}<0.01)$. The average improvement in exercise endurance was $2.2 \mathrm{~min}$, with a $95 \%$ confidence interval of 1.3-3.3 min. Reasons to stop exercise on IPS5 and IPS10 did not differ from exercise without IPS. Thirty-three patients stopped exercise as a result of intolerable dyspnoea and 12 patients stopped owing to a combination of dyspnoea and leg discomfort.

In figure 1, an identity plot is shown of endurance of the exercise test without IPS and endurance on IPS10. Exercise endurance with IPS10, compared with exercise endurance

Table 3. - St George's respiratory questionnaire

\begin{tabular}{lrc}
\hline & \multicolumn{1}{c}{ Value } & $\%$ maximum \\
\hline Symptoms & $318 \pm 160$ & $47 \pm 24$ \\
Activities & $914 \pm 212$ & $76 \pm 18$ \\
Impacts & $896 \pm 442$ & $42 \pm 21$ \\
Total score & $2127 \pm 678$ & $53 \pm 17$ \\
\hline
\end{tabular}


Table 4. - Physiological responses in the 45 subjects during constant-load exercise tests

\begin{tabular}{|c|c|c|c|c|}
\hline & End-exercise without IPS & End-exercise IPS5 & Iso-time IPS10 & End-exercise IPS10 \\
\hline Exercise time min & $4.3 \pm 2.6$ & $4.4 \pm 2.9$ & $4.4 \pm 2.9$ & $6.3 \pm 6.7 *$ \\
\hline Heart rate beats $\cdot \min ^{-1}$ & $115 \pm 15$ & $114 \pm 14$ & $114 \pm 14$ & $114 \pm 17$ \\
\hline $\mathrm{Sp}, \mathrm{O}_{2} \%$ & $90 \pm 4$ & $90 \pm 4$ & $91 \pm 4^{*}$ & $90 \pm 4$ \\
\hline$V^{\prime} \mathrm{E} \mathrm{Lmin}^{-1}$ & $32.1 \pm 11.4$ & $31.7 \pm 9.6$ & $31.7 \pm 9.3$ & $34.0 \pm 10.0^{*}$ \\
\hline$V \mathrm{~T} \mathrm{~L}$ & $1.17 \pm 0.32$ & $1.38 \pm 0.36^{\#}$ & $1.50 \pm 0.40^{*}$ & $1.48 \pm 0.37 *$ \\
\hline $\mathrm{RR}$ breaths $\cdot \mathrm{min}^{-1}$ & $27 \pm 6$ & $23 \pm 5^{\#}$ & $21 \pm 5^{*}$ & $23 \pm 5^{*}$ \\
\hline$V^{\prime} \mathrm{O}_{2} \mathrm{~L} \cdot \mathrm{min}^{-1}$ & $0.77 \pm 0.25$ & $0.80 \pm 0.26$ & $0.76 \pm 0.25^{\bullet}$ & $0.83 \pm 0.25^{*}$ \\
\hline$V^{\prime} \mathrm{CO}_{2} \mathrm{~L} \cdot \mathrm{min}^{-1}$ & $0.72 \pm 0.26$ & $0.77 \pm 0.30^{\#}$ & $0.74 \pm 0.29 *$ & $0.81 \pm 0.29 *$ \\
\hline RER & $0.92 \pm 0.07$ & $0.95 \pm 0.09^{\#}$ & $0.96 \pm 0.09 *$ & $0.97 \pm 0.08 *$ \\
\hline$t \mathrm{i} / t$ tot & $0.34 \pm 0.05$ & & & \\
\hline \multicolumn{5}{|l|}{ IC L } \\
\hline Rest & $2.04 \pm 0.55$ & & & \\
\hline End exercise & $1.54 \pm 0.37$ & & & \\
\hline
\end{tabular}

Data are presented as mean \pm 1 SD unless otherwise stated. IPS: inspiratory pressure support; IPS5: IPS of $5 \mathrm{cmH}_{2} \mathrm{O}$ on exercise endurance; IPS10: IPS of $10 \mathrm{cmH}_{2} \mathrm{O}$ on exercise endurance; $S \mathrm{p}, \mathrm{O}_{2}$ : oxyhaemoglobin saturation measured with pulse oximetry; $V^{\prime} \mathrm{E}$ : minute ventilation; $V \mathrm{~T}$ : tidal volume; RR: respiratory rate; $V^{\prime} \mathrm{O}_{2}$ : oxygen uptake; $V^{\prime} \mathrm{O}_{2}$ : carbon dioxide production; RER: respiratory exchange ratio; ti/ttot: ratio inspiratory time to total breath time; IC: inspiratory capacity. ${ }^{*}: \mathrm{p}<0.05$ versus exercise without IPS and IPS5; ${ }^{\#}: \mathrm{p}<0.05$ versus exercise without IPS; ${ }^{\uparrow}$ : $\mathrm{p}<0.05$ versus exercise with IPS5.

without IPS, was higher in 27 patients $(60 \%)$, remained unaltered in four patients $(9 \%)$ and was lower in 14 patients $(31 \%)$. In 15 patients, the improvement in exercise endurance was $\geqslant 100 \%$ (fig. 2).

\section{Effects of inspiratory pressure support on physiological responses}

Compared with end-exercise with IPS5, IPS10 resulted at the isotime moment in a statistically significant increase in tidal volume $(V \mathrm{~T})$ and lower respiratory rate $(\mathrm{RR})$, whereas $V^{\prime} \mathrm{E}$ did not differ. Also $V^{\prime} \mathrm{O}_{2}$ and carbon dioxide production $\left(V^{\prime} \mathrm{CO}_{2}\right)$ were significantly lower at the isotime moment. $V^{\prime} \mathrm{E}$, $V \mathrm{~T}, V^{\prime} \mathrm{O}_{2}$ and $V^{\prime} \mathrm{CO}_{2}$ were significantly higher at end exercise during exercise with IPS10, compared with end exercise with IPS5 (table 3).

\section{Determinants of effect of inspiratory pressure support on exercise endurance}

In single regression analysis, significant correlations (r) were found for the improvement in exercise endurance with

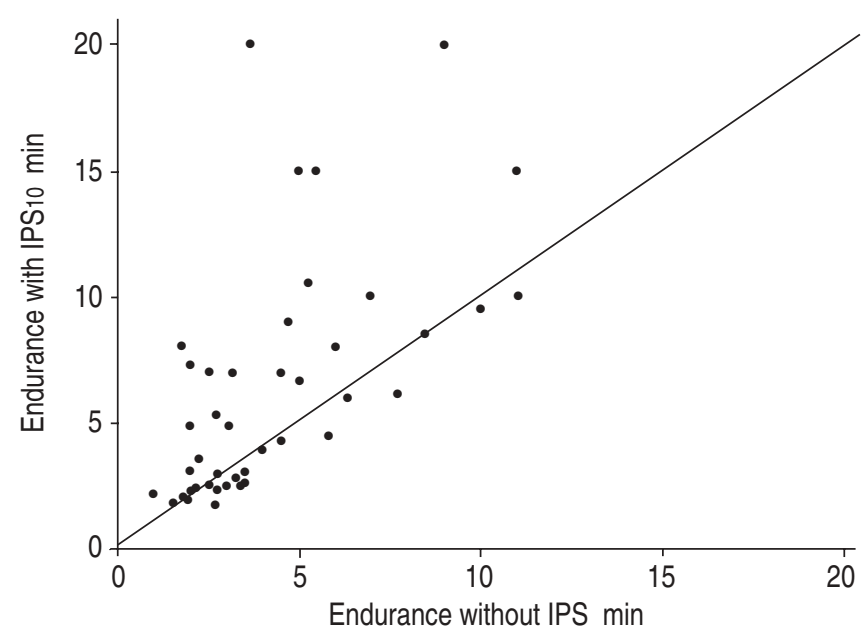

Fig. 1.-Identity plot of exercise endurance without inspiratory support pressure (IPS) and with IPS of $10 \mathrm{cmH}_{2} \mathrm{O}$ (IPS10).

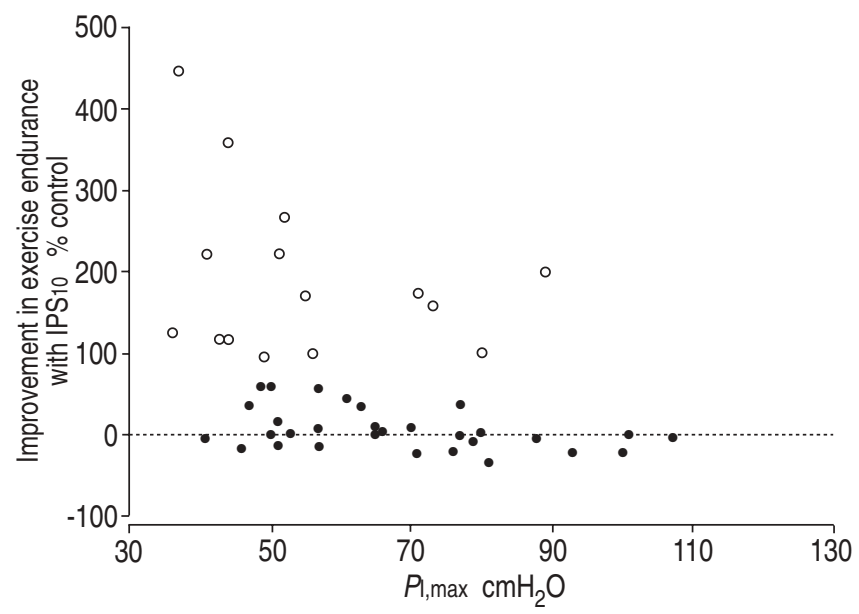

Fig. 2. - Relationship $(\mathrm{r}=-0.49, \mathrm{p}=0.001)$ between improvement in exercise endurance and maximal inspiratory pressure ( $\left.P_{\mathrm{I}, \max }\right)$. IPS10: inspiratory pressure support of $10 \mathrm{cmH}_{2} \mathrm{O}$. - patients with a change in exercise endurance $<100 \%, \mathrm{n}=15 ; \bigcirc$ : patients with a change in exercise endurance of $\geqslant 100 \%$ (at least doubled).

IPS10 and $P \mathrm{I}, \max (\mathrm{r}=-0.49, \mathrm{p}<0.01), P$ E, $\max (\mathrm{r}=-0.33, \mathrm{p}<0.04)$, $P \mathrm{I}$,end $(\mathrm{r}=-0.39, \mathrm{p}<0.02)$, end exercise $V^{\prime} \mathrm{E}$ in the constant-load test without IPS ( $\mathrm{r}=-0.42, \mathrm{p}<0.01), P \mathrm{a}, \mathrm{CO}_{2}$ at rest $(\mathrm{r}=0.37$, $\mathrm{p}<0.03), \quad P \mathrm{a}, \mathrm{CO}_{2}$ at peak exercise during the maximal incremental exercise test $(\mathrm{r}=0.37, \mathrm{p}<0.03)$ and the Activity component of the SGRQ $(\mathrm{r}=0.38, \mathrm{p}<0.05)$. No statistically significant correlation coefficients were found between improvement in exercise endurance and single-breath diffusing capacity $(\mathrm{r}=0.14, \mathrm{p}=0.41)$, the change in $\mathrm{IC}$ during the unsupported constant-load exercise test $(\mathrm{r}=0.15, \mathrm{p}=0.34)$ and the MRC score $(r=0.14, p=0.34)$.

In stepwise multiple regression analysis, the only factor significantly contributing to the improvement in exercise endurance as a result of the application of IPS10 during exercise appeared to be $P \mathrm{I}$,max. The computed regression model is

Improvement in exercise endurance $=238-2.8 \times P_{\mathrm{I} \text {, } \max }$ which could explain $24 \%$ of the variance in outcome $(\mathrm{p}<0.01)$. In figure 2 the relationship is shown between improvement in exercise endurance and $P \mathrm{I}$,max. 


\section{Discussion}

The main finding of the present study is that the application of NIVS during exercise, in the form of IPS10, resulted in a statistically significant increase in exercise endurance compared with a test without IPS, as well as compared with exercise with IPS5, in patients with moderate-to-severe COPD. In contrast, IPS5 did not affect exercise endurance compared with exercise without IPS. Despite the inclusion of patients on the basis of a ventilatory impaired exercise capacity, IPS10 resulted in only 33\% of the population in a marked increase in exercise endurance. The effects of IPS10 on exercise endurance could be predicted to a small degree (24\%) on the basis of the PI,max.

To the best of the authors' knowledge, this is the first study in which the effects of NIVS were evaluated not only by comparing the effects of two intensities of IPS on constantload exercise endurance, i.e. IPS5 and IPS10, but also by comparing these effects to exercise endurance without IPS. The statistically significant increase in exercise endurance due to IPS10 of $\sim 2$ min confirms the results of other studies on the effects of IPS $[6,22]$. Interpretation of the significance of this effect is hampered for two reasons. At first, no data are available on the reliability of the measurement of the effect of IPS on exercise endurance. In the present study, exercise endurance on IPS was higher in $27(60 \%)$ of the patients. However, in only 15 of the 45 patients $(33 \%)$ the improvement in exercise endurance on IPS exceeded the upper limit of the $95 \%$ confidence interval ( $>3.3 \mathrm{~min}$ ) of the average improvement. In these 15 patients, exercise endurance improved, on average by $7.5 \mathrm{~min}$, and at least doubled on IPS. Secondly, the minimal clinically important difference in constant-load cycle endurance has yet to be determined [19].

In the present study, the effects of two different intensities of IPS were examined. This was because it could be argued that application of IPS of a low intensity may have a negative effect on exercise performance as a result of insufficient compensation for the increase in work of breathing, due to the resistance of the tubing circuit and valve system of the ventilator [5]. In the present study, no difference in exercise endurance was present between exercise without IPS and exercise with IPS5, indicating the absence of a negative effect of IPS5 on exercise performance. The authors are unaware of studies in which the effects of CPAP1 during exercise were compared with exercise without ventilatory support. However, O'DONNELL et al. found a statistically, significantly lower exercise endurance during exercise with CPAP1 compared with exercise with IPS5 in patients with chronic heart failure [23]. Their findings, combined with the results of the present study, may suggest that CPAP1 has a negative influence on exercise endurance compared with exercise without IPS.

The increase in $V \mathrm{~T}$ and decrease in RR during exercise with IPS is in agreement with earlier studies [7, 22]. Due to the resulting improved alveolar ventilation, it may explain the slightly higher oxygen saturation at the isotime moment during exercise with IPS10 compared with end exercise without IPS and IPS5. The reduction in $V^{\prime} \mathrm{O}_{2}$ and $V^{\prime} \mathrm{CO}_{2}$ found in the present study at the isotime moment during exercise with IPS10 compared with end exercise with IPS5 supports the finding of the studies by MALTAIS et al. [7] and PETROF et al. [8] that inspiratory muscles are less loaded during exercise with IPS10. In patients with COPD, $V^{\prime} \mathrm{O}_{2}$ of the ventilatory muscles during exercise may be a substantial part of the total $V^{\prime} \mathrm{O}_{2}$ [24]. In addition, during ventilator weaning, BROCHARD et al. [25] found a good correlation between, on the one hand, the reduction in respiratory muscle activity due to IPS, and, on the other hand, the lower $V^{\prime} \mathrm{O}_{2}$ of contracting ventilatory muscles.
In the present study, improvement in exercise endurance due to the application of IPS10 compared with unsupported exercise, ranged from a deterioration of $1.6 \mathrm{~min}(-36 \%)$ to an improvement of $16.3 \mathrm{~min}(+445 \%)$. To date, this is the first study attempting to predict the extent of improvements in exercise endurance due to IPS10 on the basis of pulmonary function and respiratory muscle function indices. A significant negative association was found $(\mathrm{r}=-0.49, \mathrm{p}<0.01)$ between $P I$, max and the increase in exercise endurance. This finding concurs with the hypothesis that the improvements in exercise endurance due to the application of IPS are related to inspiratory muscle weakness. POLKEY et al. [26] have demonstrated, in patients with COPD, that IPS during exercise may result in a delay in the initiation of the fatigue process in the inspiratory muscles. Since weakness makes the muscles susceptible to fatigue, it is likely that COPD patients with inspiratory muscle weakness may benefit most from unloading the inspiratory muscles [27]. The significant correlation between improvement in exercise endurance on IPS10 and a high $\mathrm{Pa}, \mathrm{CO}_{2}$, at rest and at maximal exercise, is also in keeping with the observed association between inspiratory muscle weakness and carbon dioxide retention in patients with COPD [28]. The absence of significant correlation coefficients between, on the one hand, improvements in exercise endurance, and, on the other hand, diffusing capacity of the lung for carbon monoxide and the decrease in IC during unsupported constant-load exercise, suggest that regardless of the severity of the altered pulmonary mechanics in patients with COPD, NIVS results in improved exercise performance.

A potentially important mechanism of NIVS to improve exercise performance may be a reduction in exertional dyspnoea [7, 22]. However, the authors did not attempt to measure such an effect because the primary aim of the present study was to measure the effects of two intensities of IPS on exercise endurance due to IPS10. In the present study, the order of testing was randomised, and thus dyspnoea ratings should have been collected during the exercise tests very often, i.e. every $30 \mathrm{~s}$ to allow appropriate comparisons of dyspnoea ratings between tests at identical exercise durations. It was anticipated that an accurate evaluation of the effect of IPS on exercise endurance would have been disturbed by such frequent dyspnoea ratings. In the present study, exertional dyspnoea contributed significantly to patients' exercise intolerance. Moreover, a statistically significant correlation was observed between the Activity component of the SGRQ and the increase in exercise endurance due to the application of IPS. This implies that patients with the highest impact of chronic exertional dyspnoea during activities of daily living may benefit the most from IPS to improve their training tolerance.

Despite the identification of determinants of a positive response to IPS in the present study, the predictive validity of these determinants was low. In a multiple regression model, $P$ I, max was selected, explaining only $24 \%$ of the variance in cycle endurance improvement. As a consequence, it is not possible to predict the individual exercise responses to IPS reliably. If training on assisted ventilation is considered, patients should be put through a trial session. However, patients without inspiratory muscle weakness $(P \mathrm{I}, \max >$ $\pm 70 \mathrm{cmH}_{2} \mathrm{O}$ ) are the least likely to respond to IPS during exercise and should probably not be considered primary candidates for such an intervention.

The significant inverse correlation between improvement in exercise endurance and end exercise $V^{\prime} \mathrm{E}$ in the constant-load exercise test without IPS may indicate an association between the impaired ventilatory capacity of the respiratory system of patients and the positive effect of IPS10 on exercise ability. Alternatively, this significant correlation may be caused by a "ceiling effect" due to the maximal capacity of the ventilator. 
The ventilator used in the present study could support ventilation to a maximal level of $50 \mathrm{~L} \cdot \mathrm{min}^{-1}$. It is possible that better results could be obtained by the use of a ventilator with a better technical performance than the ventilator used in the present study. However, only three patients had an end exercise $V^{\prime} \mathrm{E}$ of $\geqslant 50 \mathrm{~L} \cdot \mathrm{min}^{-1}$ in the constant-load test without IPS, making it a less likely explanation. In addition, leaving out the results of these three patients did not affect the outcome of the analysis.

Blinding of patients was applied with respect to the order in which tests with IPS5 and IPS10 were performed. However, blinding of the observer to the application of IPS during exercise was in this experimental set-up not possible. The difference in sound intensity produced by the ventilator between IPS5 and IPS10 could easily be recognised by the observer. As a result, expectation bias could have influenced the results of the present study. However, the absence of a difference in the physiological responses at end exercise between exercise without IPS and with IPS5 suggests equality in the patients' efforts (and observer encouragements) between these tests.

Exercise training has been accepted as key component of rehabilitation programmes in patients with COPD, but the optimal length, duration, frequency and intensity of training sessions remain to be determined [29]. Lower limb muscle alterations, like weakness and fatigability are frequently found in patients with COPD and contribute significantly to the impaired exercise capacity [30]. Exercise training on NIVS, by increasing the ventilatory capacity and/or reducing the ventilatory load, may allow for higher training loads, and hence, a better outcome. Conversely, exercise on NIVS reduces the load on the respiratory muscles, which may prevent an adequate training stimulus to these muscles. Interestingly, GARROD et al. [31] found improvements in respiratory muscle function from general exercise training only when NIVS, applied during the night, was added.

To date, there are three studies published on the effects of training on noninvasive ventilatory support. None of these studies reported negative effects of training on noninvasive ventilatory support on respiratory muscle function [32-34]. Since outcomes with respect to improvements in exercise capacity were inconsistent, more randomised controlled studies are required to determine the effect, if any, of exercise training on noninvasive ventilatory support on the outcome of rehabilitation programmes in patients with chronic obstructive pulmonary disease.

Acknowledgements. The authors would like to thank L. van der Schaaf, specialist respiratory nurse, and J. Berkovits, M. van Hengstum, P.M. Hooghiemstra, P. Kunst, P.I. van Spiegel, W.F.M Strankinga and A. Vonk Noordegraaf, chest physicians, for their efforts in the recruitment of patients for this study.

\section{References}

1. Lacasse Y, Brossea L, Milne S, et al. Pulmonary rehabilitation for chronic obstructive pulmonary disease. Cochrane Database Syst Rev 2002; 3: CD003793.

2. Lacasse Y, Guyatt GH, Goldstein RS. The components of a respiratory rehabilitation program: a systematic overview. Chest 1997; 111: 1077-1088.

3. Ambrosino N. Exercise and noninvasive ventilatory support. Monaldi Arch Chest Dis 2002; 55: 242-246.

4. van 't Hul AJ, Kwakkel G, Gosselink R. The acute effects of non-invasive ventilatory support during exercise on exercise endurance and dyspnea in patients with COPD: a systematic review. J Cardiopulm Rehabil 2002; 22: 290-297.

5. Brochard L, Rua F, Lorino H, Lemaire F, Harf A.
Inspiratory pressure support compensates for the additional work of breathing caused by the endotracheal tube Anaesthesiology 1991; 75: 739-745.

6. Keilty SE, Ponte J, Fleming TA, Moxham J. Effect of inspiratory pressure support on exercise tolerance and breathlessness in patients with severe stable chronic obstructive pulmonary disease. Thorax 1994; 49: 990-994.

7. Maltais F, Reissmann H, Gottfried SB. Pressure support reduces inspiratory effort and dyspnea during exercise in chronic airflow obstruction. Am J Respir Crit Care Med 1995; 151: 1027-1033.

8. Petrof BJ, Calderini E, Gottfried SB. Effect of CPAP on respiratory effort and dyspnea during exercise in severe COPD. J Appl Physiol 1990; 69: 179-188.

9. Pauwels RA, Buist AS, Calverley PM, et al. Global strategy for the diagnosis, management, and prevention of chronic obstructive pulmonary disease. NHLBI/WHO Global Initiative for Chronic Obstructive Lung Disease (GOLD) Workshop summary. Am J Respir Crit Care Med 2001; 163: 1256-1276.

10. Quanjer PH, Tammeling GJ, Cotes JE, et al. Lung volumes and forced ventilatory flows. Report Working Party Standardization of Lung Function Tests, European Community for Steel and Coal. Official Statement of the European Respiratory Society. Eur Respir J 1993; 6: Suppl. 16, 5-40.

11. Black LF, Hyatt RE. Maximal respiratory pressures: normal values and relationship to age and sex. Am Rev Respir Dis 1969; 99: 696-702.

12. Martyn JB, Moreno RH, Pare PD, Pardy RL. Measurement of inspiratory muscle performance with incremental threshold loading. Am Rev Respir Dis 1987; 135: 919-923.

13. van 't Hul AJ, Chadwick-Straver RVM, Sol G, Boonstra A, Wagenaar RC. Maximal incremental inspiratory threshold loading: test-retest reliability and a range of reference. Eur Respir J 1998; 12: Suppl. 28, 353s.

14. Roca J, Whipp BJ, Agusti AN, et al. Clinical exercise testing with reference to lung disease - indications, standardization and interpretation strategies. Eur Respir J 1997; 10: 26622689.

15. Jones NL, Makrides L, Hitchcock C, Chypchar T, McCartney P. Normal standards for an incremental progressive cycle ergometer test. Am Rev Respir Dis 1985; 131: 700-708.

16. Jones NL, Summers E, Killian KJ. Influence of age and stature on exercise capacity during incremental cycle ergometry in men and women. Am Rev Respir Dis 1989; 140: $1373-1380$.

17. Carter R, Peavler M, Zinkgraf S, Williams J, Fields S. Predicting maximal exercise ventilation in patients with chronic obstructive pulmonary disease. Chest 1987; 92: 253259.

18. O'Donnell DE, Lam M, Webb KA. Measurement of symptoms, lung hyperinflation, and endurance during exercise in chronic obstructive pulmonary disease. Am J Respir Crit Care Med 1998; 158: 1557-1565.

19. van 't Hul AJ, Gosselink R, Kwakkel G. Constant-load cycle endurance performance: test-retest reliability and validity in patients with COPD. J Cardiopulm Rehabil 2003; 23: 143-150.

20. Bestall JC, Paul EA, Garrod R, Garnham R, Jones PW, Wedzicha JA. Usefulness of the Medical Research Council (MRC) dyspnoea scale as a measure of disability in patients with chronic obstructive pulmonary disease. Thorax 1999; 54: 581-586.

21. Jones PW, Quirk FH, Baveystock CM, Littlejohns P. A selfcomplete measure of health status for chronic airflow limitation. The St. George's Respiratory Questionnaire. Am Rev Respir Dis 1992; 145: 1321-1327.

22. Bianchi L, Foglio K, Pagani M, Vitacca M, Rossi A, Ambrosino M. Effects of proportional assist ventilation on exercise tolerance in COPD patients with chronic hypercapnia. Eur Respir J 1998; 11: 422-427.

23. O'Donnell DE, D'Arsigny C, Raj S, Abdollah H, Webb KA. Ventilatory assistance improves exercise endurance in stable 
congestive heart failure. Am J Respir Crit Care Med 1999; 160: 1804-1811.

24. Evison H, Cherniack RM. Ventilatory cost of exercise in chronic obstructive pulmonary disease. J Appl Physiol 1968; 25: 21-27.

25. Brochard L, Harf A, Lorino H, Lemaire F. Inspiratory pressure support prevents diaphragmatic fatigue during weaning from mechanical ventilation. Am Rev Respir Dis 1989; 139: 513-521.

26. Polkey MI, Kyroussis D, Mills GH, et al. Inspiratory pressure support reduces slowing of inspiratory muscle relaxation rate during exhaustive treadmill walking in severe COPD. Am J Respir Crit Care Med 1996; 154: $1146-1150$.

27. Begin P, Grassino A. Inspiratory muscle dysfunction and chronic hypercapnia in chronic obstructive pulmonary disease. Am Rev Respir Dis 1991; 143: 905-912.

28. Rochester DF. Respiratory muscle weakness, pattern of breathing, and $\mathrm{CO}_{2}$ retention in chronic obstructive pulmonary disease. Am Rev Respir Dis 1991; 143: 901-903.

29. Morgan DL, Calverly PMA, Clark CJ, et al. Pulmonary rehabilitation (BTS statement). British Thoracic Society
Standards of Care Subcommittee on Pumonary Rehabilitation. Thorax 2001; 56: 827-834.

30. Saey D, Debigare R, LeBlanc P, et al. Contractile leg fatigue after cycle exercise: a factor limiting exercise in patients with COPD. Am J Respir Crit Care Med 2003; 168: 425-430.

31. Garrod R, Mikelsons C, Paul EA, Wedzicha JA. Randomized controlled trial of domiciliary noninvasive positive pressure ventilation and physical training in severe chronic obstructive pulmonary disease. Am J Respir Crit Care Med 2000; 162: 1335-1341.

32. Hawkins P, Johnson LC, Nikoletou D, et al. Proportional assist ventilation as an aid to exercise training in severe chronic obstructive pulmonary disease. Thorax 2002; 57: 853-859.

33. Johnson JE, Gavin DJ, Adams-Dramiga S. Effects of training with heliox and noninvasive positive pressure ventilation on exercise ability in patients with severe COPD. Chest 2002; 122: 464472.

34. Bianchi L, Foglio K, Porta R, Baiardi R, Vitacca M, Ambrosino N. Lack of additional effect of adjunct of assisted ventilation to pulmonary rehabilitation in mild COPD patients. Respir Med 2002; 96: 359-367. 